\title{
INTRA-ARTERIAL PHARMACOKINETICS AND PULMONARY FIRST-PASS OF LEVAMISOLE IN RABBITS
}

\author{
PABLO PEREDA, JUAN J. GARCÍA, MATILDE SIERRA, NÉLIDA FERNÁNDEZ*, \\ ANA M. SAHAGUN and M. JOSE DIEZ \\ Área de Farmacología, Departamento de Farmacología, Toxicología y Enfermería, Universidad de León, \\ 24071, León, Spain
}

Accepted 1 March 2002

\begin{abstract}
The pharmacokinetics of levamisole after intra-arterial administration of $12.5,16$ and $20 \mathrm{mg} \mathrm{kg}^{-1}$ was investigated in rabbits. After compartmental analysis, the disposition of levamisole was well described by a two-compartment open model with mean values \pm SD of: $\alpha=0.1650 \pm$ $0.0839,0.1611 \pm 0.0298,0.2312 \pm 0.0540 \mathrm{~min}^{-1}$, and $\beta=0.0118 \pm 0.0022,0.0125 \pm$ $0.0026,0.0120 \pm 0.0024 \mathrm{~min}^{-1}$, for the three doses studied, respectively. There were no doserelated differences (one-way analyses of variance (ANOVA), $P \leq 0.05$ ) in $\alpha, \beta$, total body clearance $(\mathrm{Cl})$ and volume of distribution at steady state $\left(V_{\mathrm{ss}}\right)$. The AUC increased significantly with the doses $\left(249.7,376.7\right.$ and $\left.562.5 \mu \mathrm{g} \mathrm{min} \mathrm{ml}^{-1}\right)$. After non-compartmental analysis there were no significant differences in plasma elimination rate constant $(\lambda)$, MRT and $V_{\text {ss }}$ as a function of dose, but these differences were significant for $C l$, between 16 and $20 \mathrm{mg} \mathrm{kg}^{-1}$, and AUC (one-way ANOVA, $P \leq 0.05)$. The two-way ANOVA showed no significant differences between the values obtained for the three doses when $\lambda-\beta, C l, V_{\mathrm{ss}}$ and $V_{\mathrm{a}}$ were compared while AUC showed significant changes. On the other hand, the pharmacokinetic analysis (compartmental and non-compartmental) showed significant differences in AUC, $\mathrm{Cl}, V_{\mathrm{ss}}$ and $V_{\mathrm{a}}$, but there were no significant differences when $\lambda-\beta$ were compared. The slow clearance of levamisole by rabbit lung compared to a high pulmonary blood flow rate makes the possibility of significant first-pass lung metabolism unlikely in this animal species. $\quad$ (c) 2002 Elsevier Science Ltd. All rights reserved.
\end{abstract}

KEY WORDS: levamisole, pulmonary first-pass, rabbits.

\section{INTRODUCTION}

Levamisole (1-2,3,5,6-tetrahydro-6-phenylimidazo$[2,1-b]$ thiazole $)$ is a broad-spectrum anthelmintic active against most gastrointestinal and pulmonary nematodes which parasitize man and domestic animals $[1,2]$.

Besides its anthelmintic activity, levamisole also possesses immunomodulatory properties $[2,3]$. On the basis of these properties this drug has been used to improve vaccine therapy in numerous species $[4,5]$ and for treatment of different diseases affecting domestic animals $[6,7]$. Its effectiveness as an adjuvant in cancer therapy and its immunomodulating effects have also been proved in men and animals [8, 9].

Organs other than liver possess ability to eliminate drugs, though their metabolic capacity is low [10]. Lungs, in addition to their role in gas exchange, have been shown to perform non-respiratory functions

\footnotetext{
*Corresponding author. E-mail: dftnfm@unileon.es.
}

such as the uptake, accumulation and metabolism of numerous chemicals $[11,12]$, particularly some basic and volatile drugs, environmental toxicants and endogenous substances [10].

The purpose of this study is to establish several pharmacokinetic parameters of levamisole after intraarterial administration in the rabbit, a target species for this drug and estimate the pulmonary clearance and extraction ratio during the first-passage through the lung by comparison of plasma levamisole concentrations after intravenous [13] and intra-arterial administration at 12.5, 16 and $20 \mathrm{mg} \mathrm{kg}^{-1}$ in rabbits.

\section{METHODS}

\section{Animals}

Fifteen healthy male New Zealand white rabbits weighing between 2.500 and $3.400 \mathrm{~kg}$ were used. Animals were housed in individual cages. Environmental 
conditions were as follows: a $12 \mathrm{~h}$ light-dark cycle at $19 \pm 2{ }^{\circ} \mathrm{C}$ room temperature and $55 \pm 10 \%$ relative humidity. Rabbits were allowed water and rabbit chow ad libitum.

\section{Treatment and blood sampling}

Rabbits were randomly distributed in three groups of five animals each depending on the administered dose (12.5, 16 and $20 \mathrm{mg} \mathrm{kg}^{-1}$ ).

The animals were anaesthetized with sodium pentobarbital $\left(30 \mathrm{mg} \mathrm{kg}^{-1}\right.$, intravenous administration in the ear marginal vein), and the left carotid artery was canulated with a Silastic Medical Grade Tubing ${ }^{\circledR}$ catheter $1.02 \mathrm{~mm}$ ID $\times 2.16$ OD .

Levamisole $\mathrm{HCl}$ administration was carried out after total recovery from anaesthesia was achieved. Each animal received the corresponding dose dissolved in $0.3 \mathrm{ml}$ sterile water through the arterial catheter.

Heparinized blood samples $(3 \mathrm{ml})$ were collected from the carotid artery at $0,5,10,15,20,25,30,60,90,120$, 150, 180, 210 and $240 \mathrm{~min}$ after drug administration. Immediately after collection, plasma was separated by centrifugation and stored at $-20^{\circ} \mathrm{C}$ until analysed.

\section{Analysis}

Levamisole plasma concentrations were determined by high-performance liquid chromatography with UV detection, following the method previously described by García et al. 1990 [14]. The lowest detectable concentration of levamisole in plasma was $0.08 \mu \mathrm{g} \mathrm{ml}^{-1}$.

\section{Pharmacokinetic analysis}

Pharmacokinetic analysis was performed based on a compartmental as well as on a non-compartmental description of the data observed.

Compartmental analysis. Individual plasma concentration-time profiles of levamisole after intra-arterial (i.a.) administration were analysed using the PCNONLIN computer program [15] with reciprocal concentration weights $(1 / C)$. Initial estimates of the parameters were determined by the JANA program [16]. The pharmacokinetic model (one, two or three compartments) best describing the experimental data was determined by application of Akaike's information criterion (AIC) [17] and graphical analysis of weighted residuals. The equation for the two-compartment open model, used to describe levamisole pharmacokinetics was:

$$
C=A e^{-\alpha t}+B e^{-\beta t}
$$

where $\alpha$ and $\beta$ are the disposition constants, and $A$ and $B$ are their respective zero time intercepts. The other compartmental parameters were calculated by standard methods [18].

Non-compartmental analysis. The model-independent pharmacokinetic parameters were calculated using expressions based on statistical moments theory [19] and formulae described by Gibaldi and Perrier, 1982 [18]. The plasma elimination rate constant $(\lambda)$ was calculated by least square regression of the logarithm of plasma concentration versus time curve over the terminal elimination phase.

The area under the plasma concentration-time curve from time zero to the last determined sample time $\left(\mathrm{AUC}_{0-\mathrm{t}}\right)$ was calculated by the trapezoidal rule, and the total area under the plasma concentration versus time curve (AUC) by adding $\mathrm{AUC}_{0-\mathrm{t}}$ to the residual area $\mathrm{AUC}_{\mathrm{t}-\infty}$ (calculated from $C_{\mathrm{t}}$, the last experimental plasma concentration, divided by the terminal slope, $\lambda$ ). The total area under the first moment curve (AUMC) from time zero to time infinite was calculated by adding $\mathrm{AUMC}_{0-\mathrm{t}}$ to $\mathrm{AUMC}_{\mathrm{t}-\infty}$. The area from time 0 to $t$ was determined using the trapezoidal rule, and the area from time $t$ to $\infty$ was given by: $\mathrm{AUMC}_{\mathrm{t}-\infty}=t \cdot C_{\mathrm{t}} / \lambda+\mathrm{C}_{\mathrm{t}} / \lambda^{2}$.

The mean residence time (MRT) was determined by using the equation: MRT $=$ AUMC/AUC.

Total body clearance was calculated from the quotient of the dose $(D)$ and AUC. The terminal volume of distribution $\left(V_{\mathrm{a}}\right)$ was calculated from the ratio of the total body clearance $(\mathrm{Cl})$ and the terminal slope $(\lambda)$. The volume of distribution at steady state $\left(V_{\mathrm{ss}}\right)$ was determined by using the equation: $V_{\mathrm{ss}}=\mathrm{MRT} \times$ dose/AUC.

Pulmonary first-pass effect studies. In order to determine if levamisole undergoes pulmonary first-pass effect, data obtained after intra-arterial administration were compared to those previously obtained after intravenous administration [13].

Pulmonary clearance $\left(C l_{\mathrm{p}}\right)$ and extraction ratio $\left(E_{\mathrm{p}}\right)$ were calculated by using the equations: $C l_{\mathrm{p}}=\left(C l_{\text {tot }}\right)_{\text {i.v. }}-$ $\left(C l_{\text {tot }}\right)_{\text {i.a. }}$ and $E_{\mathrm{p}}=1-(\mathrm{AUC})_{\text {i.v. }} /(\mathrm{AUC})_{\text {i.a. }}$, respectively, where the subscripts i.v. and i.a. stand for the intravenous and intra-arterial administration, respectively [12].

\section{Statistical evaluation}

All pharmacokinetic parameters were calculated for each animal and the data presented as mean \pm SD. The data obtained from the three groups were compared for statistical significance by using the one-way and twoway analyses of variance (ANOVA). When results were significant, Duncan test was used to evaluate differences between data sets and a $P \leq 0.05$ was taken as the level of significance for all analyses. One-way analysis of variance was used to assess differences with dose and two-way ANOVA was used to test the effect of dose and pharmacokinetic analysis (compartmental and noncompartmental).

\section{RESULTS}

The values of the pharmacokinetic parameters determined by both compartmental and non-compartmental analysis for each dose after i.a. administration are given in tables I and II, respectively. 
Table I

Pharmacokinetic parameters obtained by compartmental analysis in rabbits after intra-arterial administration of levamisole ${ }^{a}$

\begin{tabular}{|c|c|c|c|}
\hline \multirow[t]{2}{*}{ Parameters } & \multicolumn{3}{|c|}{ Dose $\left(m g k g^{-1}\right)$} \\
\hline & 12.5 & 16 & 20 \\
\hline$A\left(\mu \mathrm{g} \mathrm{ml}^{-1}\right)^{b}$ & $13.02 \pm 7.99$ & $16.23 \pm 6.65$ & $50.93 \pm 44.78$ \\
\hline$B\left(\mu \mathrm{g} \mathrm{ml}^{-1}\right)^{c, d}$ & $2.037 \pm 0.436$ & $3.475 \pm 1.088$ & $4.301 \pm 0.852$ \\
\hline$\alpha\left(\min ^{-1}\right)^{b}$ & $0.1650 \pm 0.0839$ & $0.1611 \pm 0.0298$ & $0.2312 \pm 0.0540$ \\
\hline$\beta\left(\min ^{-1}\right)^{b}$ & $0.0118 \pm 0.0022$ & $0.0125 \pm 0.0026$ & $0.0120 \pm 0.0024$ \\
\hline$k_{12}\left(\min ^{-1}\right)^{b}$ & $0.0824 \pm 0.0549$ & $0.0816 \pm 0.0133$ & $0.1187 \pm 0.0297$ \\
\hline$k_{21}\left(\min ^{-1}\right)^{b}$ & $0.0344 \pm 0.0099$ & $0.0395 \pm 0.0064$ & $0.0377 \pm 0.0121$ \\
\hline$k_{10}\left(\min ^{-1}\right)^{b}$ & $0.0601 \pm 0.0311$ & $0.0525 \pm 0.0196$ & $0.0869 \pm 0.0518$ \\
\hline $\operatorname{AUC}\left(\mu \mathrm{g} \min \mathrm{ml}^{-1}\right)^{d, e}$ & $249.7 \pm 30.0$ & $376.7 \pm 63.9$ & $562.5 \pm 171.1$ \\
\hline$C l\left(\mathrm{ml} \mathrm{kg}-1 \min ^{-1}\right)^{b}$ & $50.66 \pm 6.32$ & $43.29 \pm 6.00$ & $38.43 \pm 12.08$ \\
\hline$V_{\mathrm{c}}\left(1 \mathrm{~kg}^{-1}\right)^{b}$ & $1.089 \pm 0.673$ & $0.916 \pm 0.360$ & $0.6739 \pm 0.5193$ \\
\hline$V_{\mathrm{p}}\left(1 \mathrm{~kg}^{-1}\right)^{b}$ & $2.042 \pm 0.267$ & $1.855 \pm 0.598$ & $1.820 \pm 0.922$ \\
\hline$V_{\mathrm{SS}}\left(1 \mathrm{~kg}^{-1}\right)^{b}$ & $3.130 \pm 0.627$ & $2.771 \pm 0.952$ & $2.494 \pm 1.430$ \\
\hline$V_{\mathrm{a}}\left(1 \mathrm{~kg}^{-1}\right)^{b}$ & $4.352 \pm 0.612$ & $3.626 \pm 1.063$ & $3.355 \pm 1.374$ \\
\hline$t_{1 / 2 \alpha}(\min )^{b}$ & $4.945 \pm 1.935$ & $4.434 \pm 0.887$ & $3.155 \pm 0.850$ \\
\hline$t_{1 / 2 \beta}(\min )^{b}$ & $60.34 \pm 12.10$ & $57.58 \pm 12.53$ & $59.54 \pm 12.15$ \\
\hline$t_{1 / 2 k 10}(\min )^{b}$ & $14.70 \pm 8.05$ & $14.63 \pm 4.97$ & $10.94 \pm 6.51$ \\
\hline$C_{0}\left(\mu \mathrm{g} \mathrm{ml}^{-1}\right)^{b}$ & $15.06 \pm 8.04$ & $19.70 \pm 7.24$ & $55.23 \pm 45.41$ \\
\hline AUC/dose $\left(\mathrm{kg} \mathrm{min} \mathrm{ml}^{-1}\right)^{b}$ & $0.0200 \pm 0.0024$ & $0.0235 \pm 0.0040$ & $0.0281 \pm 0.086$ \\
\hline
\end{tabular}

${ }^{a}$ Values are the mean \pm standard deviation for five rabbits. One-way ANOVA results: ${ }^{b}$ no significant differences $(P \leq 0.05)$; significant differences (Duncan test, $P \leq 0.05$ ) between: ${ }^{c} 12.5$ and $16 \mathrm{mg} \mathrm{kg}^{-1} ;{ }^{d} 12.5$ and $20 \mathrm{mg} \mathrm{kg}{ }^{-1} ;{ }^{e} 16$ and $20 \mathrm{mg} \mathrm{kg}-1$.

Table II

Pharmacokinetic parameters obtained by non-compartmental analysis in rabbits after intra-arterial administration of levamisole ${ }^{a}$

\begin{tabular}{|c|c|c|c|}
\hline \multirow[t]{2}{*}{ Parameters } & \multicolumn{3}{|c|}{ Dose $\left(m g k g^{-1}\right)$} \\
\hline & 12.5 & 16 & 20 \\
\hline$\lambda\left(\min ^{-1}\right)^{b, f}$ & $0.0105 \pm 0.0012$ & $0.0128 \pm 0.0025$ & $0.0114 \pm 0.0018$ \\
\hline $\operatorname{AUC}\left(\mu \mathrm{g} \min \mathrm{ml}^{-1}\right)^{c, d, e, g, h, i, j}$ & $205.6 \pm 27.5$ & $322.3 \pm 58.7$ & $431.3 \pm 82.1$ \\
\hline $\operatorname{AUMC}\left(\mu \mathrm{g} \min ^{2} \mathrm{ml}^{-1}\right)^{d}$ & $14977.9 \pm 3211.7$ & $22151.9 \pm 5440.4$ & $30568.5 \pm 8637.1$ \\
\hline $\operatorname{MRT}(\min )^{b}$ & $72.32 \pm 7.88$ & $68.60 \pm 12.34$ & $71.38 \pm 15.90$ \\
\hline$C l\left(\mathrm{ml} \mathrm{kg}^{-1} \min ^{-1}\right)^{e, g}$ & $61.60 \pm 7.66$ & $50.77 \pm 7.84$ & $71.87 \pm 15.30$ \\
\hline$V_{\mathrm{SS}}\left(1 \mathrm{~kg}^{-1}\right)^{b, g}$ & $4.424 \pm 0.477$ & $3.469 \pm 0.745$ & $5.167 \pm 1.647$ \\
\hline$V_{\mathrm{a}}\left(1 \mathrm{~kg}^{-1}\right)^{c, e, g}$ & $5.958 \pm 1.285$ & $4.099 \pm 1.057$ & $6.419 \pm 1.496$ \\
\hline 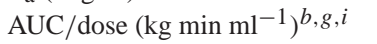 & $0.0165 \pm 0.0022$ & $0.0201 \pm 0.0037$ & $0.0216 \pm 0.0041$ \\
\hline
\end{tabular}

${ }^{a}$ Values are the mean \pm standard deviation for five rabbits. One-way ANOVA results: ${ }^{b}$ no significant differences $(P \leq 0.05)$; significant differences (Duncan test, $P \leq 0.05$ ) between: ${ }^{c} 12.5$ and $16 \mathrm{mg} \mathrm{kg}^{-1} ;{ }^{d} 12.5$ and $20 \mathrm{mg} \mathrm{kg}^{-1} ;{ }^{e} 16$ and $20 \mathrm{mg} \mathrm{kg}{ }^{-1}$. Two-way ANOVA results: ${ }^{f}$ no significant differences $(P \leq 0.05){ }^{g}$ significant differences with compartmental parameter $(P \leq 0.05)$; significant differences between: ${ }^{h} 12.5$ and $16 \mathrm{mg} \mathrm{kg}^{-1} ;{ }^{i} 12.5$ and $20 \mathrm{mg} \mathrm{kg}{ }^{-1} ;{ }^{j} 16$ and $20 \mathrm{mg} \mathrm{kg}^{-1}$.

After compartmental analysis, each individual plasma concentration-time curve was better described by a two-compartment open model following intraarterial administration in all rabbits. Plasma levamisole concentrations after each dose declined rapidly in a biexponential fashion with a rapid early $\alpha$ phase (ranging from 0.1611 to $0.2312 \mathrm{~min}^{-1}$ ) and a terminal $\beta$ phase about 15-fold lower (ranging from 0.0118 to $0.0125 \mathrm{~min}^{-1}$ ). The AUC of levamisole increased significantly with dose. The clearance values were similar (50.66, 43.29 and $38.43 \mathrm{ml} \mathrm{kg}^{-1} \mathrm{~min}^{-1}$ ) and the steady state volume of distribution ranged from 2.494 to $3.1301 \mathrm{~kg}^{-1}$. No significant differences were found when the compartmental parameters $\alpha, \beta, C l$, $V_{\mathrm{ss}}$ and AUC/dose were compared. Therefore, the pharmacokinetics followed by levamisole in the dose interval studied was linear, as the quotient AUC/dose indicates.

In the same way as in the compartmental analysis, some non-compartmental parameters were compared and there were no significant differences in $\lambda$, MRT and $V_{\text {ss }}$ for the three doses studied. The AUC of levamisole increased significantly with dose, while $C l$ values were found to be statistically different between the 16 and $20 \mathrm{mg} \mathrm{kg}^{-1}$ groups. We think that this difference may be due to interindividual variations in the $\lambda$ values used to calculate $\mathrm{Cl}$.

The two-way ANOVA showed no significant differences between the values obtained for the three doses when $\lambda-\beta, C l, V_{\mathrm{ss}}$ and $V_{\mathrm{a}}$ were compared while AUC revealed significant changes. Finally, this statistical test showed significant differences between 


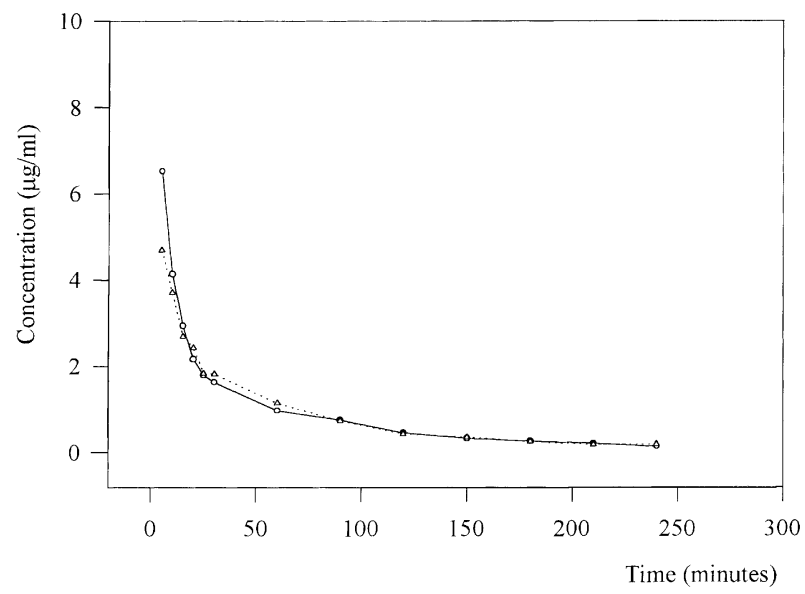

Fig. 1. Mean plasma concentrations of levamisole in rabbits after intra-arterial ( $-\infty-)$ ) and intravenous (-- --) administration of $12.5 \mathrm{mg} \mathrm{kg}^{-1}$.

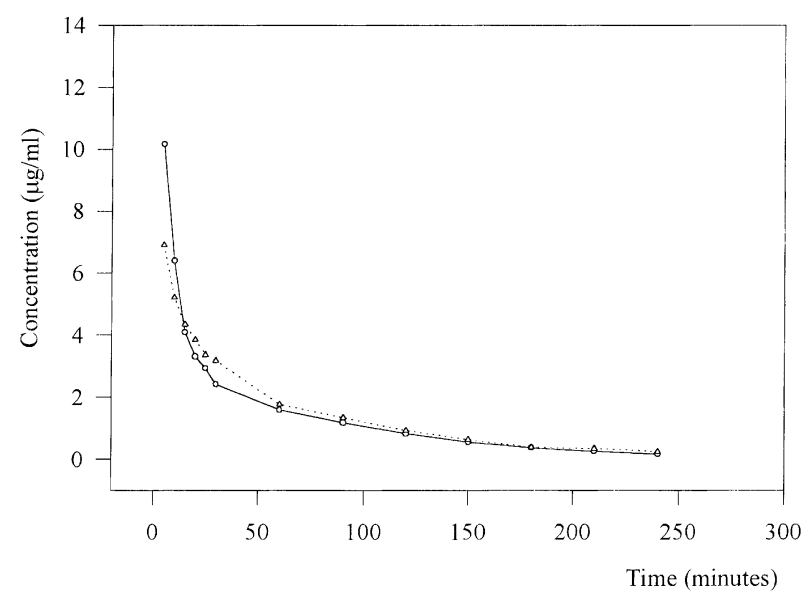

Fig. 2. Mean plasma concentrations of levamisole in rabbits after intra-arterial ( $-\infty-)$ and intravenous $\left.(--\Delta--)^{-}\right)$administration of $16 \mathrm{mg} \mathrm{kg}^{-1}$.

the values obtained using the compartmental and noncompartmental analysis when AUC, $C l, V_{\mathrm{ss}}$ and $V_{\mathrm{a}}$, were compared, but here were no significant differences between $\lambda$ and $\beta$.

Plasma levamisole concentration-time profiles following intra-arterial and intravenous [13] routes at 12.5, 16 and $20 \mathrm{mg} \mathrm{kg}^{-1}$ are shown in Figs $1-3$, respectively. In these figures it can be observed that the terminal elimination phase seemed to decline in an almost parallel fashion after i.v. and i.a. dosing.

Effect of dose on pulmonary first-pass clearance $\left(C l_{\mathrm{p}}\right)$ and extraction ratio $\left(E_{\mathrm{p}}\right)$ are summarized in table III. Each parameter fluctuated slightly with dose. In the absence of dispersion data, we have employed an approach using as compartmental reference value $C l_{\text {i.v. }}$ [13], to calculate $C l_{\mathrm{p}}$ and $E_{\mathrm{p}}$ for each animal. Under these conditions, these parameters were not dose dependent (one-way ANOVA).

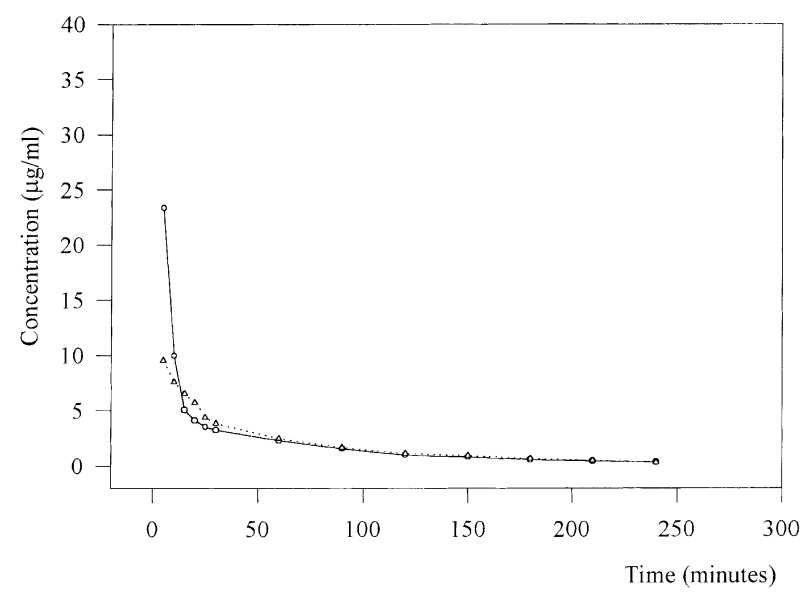

Fig. 3. Mean plasma concentrations of levamisole in rabbits after intra-arterial ( $-\infty)$ ) and intravenous (-- --$)$ ) administration of $20 \mathrm{mg} \mathrm{kg}^{-1}$.

Table III

Clearance $\left(C l_{\mathrm{p}}\right)$ and extraction ratio $\left(E_{\mathrm{p}}\right)$ for levamisole in the rabbit lung

\begin{tabular}{llcl}
\hline Parameter & \multicolumn{3}{c}{ Dose $\left(\mathrm{mg} \mathrm{kg}^{-1}\right)$} \\
& 12.5 & 16 & 20 \\
\hline$C l_{\mathrm{p}}\left(\mathrm{ml} \mathrm{kg}^{-1} \mathrm{~min}^{-1}\right)$ & 3.95 & 1.45 & 2.79 \\
$E_{\mathrm{p}}$ & 0.0215 & 0.0374 & 0.0746 \\
\hline
\end{tabular}

\section{DISCUSSION}

Levamisole showed a two-compartment disposition in rabbits. This was also reported [13] in a previous study carried out after intravenous administration at the same doses to this species. The pharmacokinetics followed by levamisole in the dose interval studied, as the quotient AUC/dose indicates, was linear.

The mean values of the $k_{12} / k_{21}, V_{\mathrm{c}} / V_{\mathrm{p}}$ And $k_{12} / k_{10}$ for each dose, as well as the volume of the central $\left(V_{\mathrm{c}}\right)$ and peripheral $\left(V_{\mathrm{p}}\right)$ compartment values, show that levamisole has a wide distribution within the rabbit, with ready access to the peripheral compartment.

It is clear that in rabbits the intact lung acts upon many compounds of diverse structure, such as imipramine [20,21], amphetamine [20], pentobarbital [22] and chlorpromazine [23].

According to organ clearance concept $[24,25], E_{\mathrm{p}}=$ $C l_{\text {int }} /\left(C l_{\text {int }}+Q\right)$, where $C l_{\text {int }}$ is the intrinsic clearance and $Q$ the blood flow. $C l_{\text {int }}$ for the pulmonary elimination of levamisole at $12.5-20 \mathrm{mg} \mathrm{kg}^{-1}$ was estimated as about $2.15-7.66 \%$ of $Q$. In this way, the slow clearance of levamisole by rabbit lung compared to a high pulmonary blood flow rate makes unlikely the possibility of significant first-pass lung metabolism in this animal species.

\section{REFERENCES}

1. Thienpont D, Vanparijs OFJ, Reaymaekers AHM, Vandenberk J, Demoen PJA, Allewijn FTN, Marsboom RPH, Niemegeers CJE, 
Schellekens KHL, Janssen PAJ. Tetramisole (R 8299), a new, potent broad spectrum anthelmintic. Nature 1966; 209: 1084-6.

2. Janssen PAJ. The story of levamisole. Prog Drug Res 1976; 20: 347-83.

3. Renoux G, Renoux M. Effect immunostimulant d'un imidazothiazole dans l'immunisation des souris contre l'infection par Brucella abortus. C R Acad Sci 1971; 272: 349-50.

4. Vyas GP, Dholakia PM, Kathiria LG. Studies on immunomodulation by levamisole along with vaccination in chicks against Ranikhet disease. Indian Vet J 1987; 64: 456-62.

5. Sharma LK, Jagadish S, Nullbagal AN. Effects of haemorrhagic septicaemia vaccination and levamisole administration on the humoral response in cross breed calves. $J$ Vet Pharmacol Ther 1990; 13: 23-8.

6. Flesh J, Harel W, Nelken D. Immunopotentiating effect of levamisole in the prevention of bovine mastitis, fetal death and endometritis. Vet Rec 1982; 111: 56-7.

7. Ishikawa H, Shimizu T. Depresion of B-lymphocytes by mastitis and treatment with levamisole. J Dairy Sci 1983; 66: 556-61.

8. Greenspan EM, Erlich R. Levamisole and new era of chemoimmunotherapy. Cancer Invest 1991; 9: 111-124.

9. Taylor DC, McEwan AD, Burke WM. Cutaneous application of levamisole to cattle: variations of bioavailability related to season and ambient temperature. Vet Rec 1983; 112-481.

10. Roth RA. Biochemistry, physiology and drug metabolismimplications regarding the role of the lungs in drug disposition. Clin Physiol Biochem 1985; 3: 66-79.

11. Minchin RF, Boyd MR. Uptake and metabolism of doxorrubicin in isolated perfused rat lung. Biochem Pharmacol 1983; 32: 2829-32.

12. Iwamoto K, Watanabe J, Aoyama Y. High capacity for pulmonary first-pass elimination of propanolol in rats. J Pharm Pharmacol 1987; 39: 1049-51.
13. García JJ, Diez MJ, Sierra M, Teran MT. Pharmacokinetics of levamisole in rabbits after intravenous administration. $J$ Vet Pharmacol Ther 1992; 15: 85-90.

14. García JJ, Diez MJ, Sierra M, Teran MT. Determination of levamisole by HPLC in plasma samples in the presence of heparin and pentobarbital. J Liq Chromatogr 1990; 13: 743-9.

15. Metzler CM, Weiner DL. PCNONLIN User's Guide. version 3.0 Lexington, KY: Statistical Consultants, 1989.

16. Dunne A. JANA: a new iterative polyexponential curve stripping program. Comp Meth Prog Biomed 1985; 20: 269-75.

17. Yamaoka K, Nakagawa T, Uno T. Aplication of Akaike's information criterion (AIC) in the evaluation of linear pharmacokinetic ecuations. J Pharmacokinet Biopharm 1978; 6: 165-75.

18. Gibaldi M, Perrier D. Pharmacokinetics. 2nd edn. New York: Marcel Dekker Inc, 1982.

19. Yamaoka K, Nakagawa T, Uno T. Statistical moments in pharmacokinetics. J Pharmacokinet Biopharm 1978; 6: 547-58.

20. Orton TC, Anderson MW, Pickett RA, Eling TE, Fouts JR. Xenobiotic accumulation and metabolism by isolated perfused rabbit lungs. J Pharmacol Exp Ther 1973; 186: 482-92.

21. Eling TE, Pickett RA, Orton TC, Anderson MW. A study of the dynamics of imipramine accumulation in the isolated perfused rabbit lungs. Drug Metab Dispos 1975; 3: 389-99.

22. Law FC, Eling TE, Bend JR, Fouts JR. Metabolism of xenobiotics by the isolated perfused lung. Drug Metab Dispos 1974; 2: 433-42.

23. García JJ, Sierra M, Diez MJ. Teran MT Uptake and accumulation of chlorpromazine by rabbit lung. An Fac Vet Leon 1991 37: $105-9$.

24. Wilkinson GR, Shand DG. A physiological approach to hepatic drug clearance. Clin Pharmacol Ther 1975; 18: 377-90.

25. Rowland M, Benet LZ, Graham GG. Clearance concepts in pharmacokinetics. J Pharmacokinet Biopharm 1973; 1: 123-36. 